\title{
Influence of Damping Ring Material on Dynamic Tensile Tests.
}

\author{
RA González-Lezcano ${ }^{1}, \mathrm{JM}$ del Río ${ }^{2}$ \\ Department of Architecture and Design. \\ Escuela Politécnica Superior, Universidad CEU San Pablo \\ Urbanización Montepríncipe, 28668 Boadilla del Monte, Madrid (Spain). \\ ${ }^{1}$ rgonzalezcano@ceu.es
${ }^{2}$ jmdrc.eps@ceu.es
}

\begin{abstract}
This paper discusses the influence of the type of materials used to fabricate the damping rings aimed for interrupting a dynamic tension experiment on the results of a modified Split Hopkinson Tension Bar (SHTB). The damping rings enclosed in an external fixture which modifies the classical SHTB play a significant role in buffering the dynamic tension experiments before the specimen reaches its failure strength. Finite-element (FE) simulations of high-strain-rate tension experiments are accomplished on Aluminum 7017-T73 alloy specimens when varying the damping rings material used. FE analyses described herein are applied to simulate the effects of the variation of the composition of the damping rings material (i.e., glass fiber-reinforced polystyrene) to provide a reference for improvement of a modified SHTB experimental apparatus and guidance for future studies in which an optimum material for the damping rings can be studied. In view of this research, it can be concluded that whilst the influence of the damping rings density, ductility, and ultimate tensile strength is definitely a relevant factor to be taken into account. On the contrary, there is no relevant effect of Poisson's ratio, yield strength, and Young's modulus when interrupting the SHTB experiment and therefore they can be excluded as factors influencing the interruption process.
\end{abstract}

Keyword-Dynamic Tension experiment, high strain rate testing, damping rings, stress-strain curve, finite element method, split Hopkinson tension bar, glass fiber-reinforced polystyrene.

\section{INTRODUCTION}

In recent years various experimental techniques have been extensively employed in characterizing the highstrain rate behaviour of engineering materials. Scientists and engineers have widely used the Split Hopkinson Bar technique to study such dynamic behaviour under high rate loading. The Split Hopkinson Bar, which may be used in compression (SHCB), tension (SHTB) and torsion (SHToB) testing, seems to be the most widespread method for material characterization at high strain rates because a well-defined stress and strain state is feasible [1-77] and material properties at high tensile stress and strain rates can consequently be obtained. SHTB is commonly used for testing different materials at average strain rates in the range between 200 and $1,500 \mathrm{~s}^{-1}$.

The working principle of SHTB has been well documented in literature [8], [9]. The classical apparatus consists of two elastic bars called the incident and the transmission bars between which a specimen of the material being tested is sandwiched. An elastic striker bar imparts a uniaxial stress pulse towards the incident bar and a tensile wave is therefore produced. After the impact, this incident wave travels along the input bar towards the specimen where it is partly reflected back into the input bar while the other part is transmitted along the output bar. The strain histories of the incident, reflected and transmitted waves are recorded by means of strain gauges suitably mounted on both bars. By adjusting the impact speed of the impactor, the strain rate can be varied.

The primary assumptions of the SHTB analysis are uniform deformation of the specimen and the absence of stresses in transverse direction [10]. Other assumptions include a constant strain rate while testing and quick equilibration of stresses in the specimen. According to the one-dimensional (1D) wave theory and the assumption of a uniaxial and homogeneous stress and strain in the specimen, the stress, strain and strain rate can be therefore calculated [11]. The 1D elastic wave theory is valid only if wave dispersion due to threedimensional effects (radial inertia of the bars) can be neglected [12]. An extensive discussion and several critical remarks on high strain rate testing can be found in [13]. Consequently, the governing principles of SHTB include 1D stress wave propagation equation, uniaxial stress and strain relations, in addition to the conservation of momentum [14]-[15]. 
Dynamic loads are not instantaneously propagated inside the impacted bodies. On the contrary, the propagation of these waves from the impact area to the entire specimen is a time-dependent variable [16]. The strain histories $\varepsilon \mathrm{i}, \varepsilon_{\mathrm{r}}$ and $\varepsilon \mathrm{t}$ corresponding to respectively the incident, reflected and transmitted wave are measured at well chosen points on the Hopkinson bars [17].

The feasibility of a FE modified SHTB model for dynamic experiments is presented in this paper. In addition, the influence of the dimensions of the damping rings inserted in a modified SHTB on the interrupted dynamic tension experiment results is discussed below. The damping rings enclosed in an external fixture which modifies the classical SHTB play a significant role in buffering the dynamic tension experiments before the specimen reaches its failure strength.

The SHTB model considerably simplifies the stress wave theory and it simultaneously offers accurate and reproducible results. However, such model simplification involves several limitations which are discussed below. The parameters of interest in SHTB model are developed considering an elastic behaviour of the bars. In relation to the specimen, both elastic and plastic deformations are considered. The below-discussed necessary equations can be obtained through a single differential element, as described by Kaiser [18] and Swantek [19].

The article developed by Gonzalez-Lezcano y del Río (2015). "Numerical analysis of the influence of the damping rings' dimensions on interrupted dynamic tension experiment results. Published in The Journal of Strain Analysis for Engineering Design was the basis for the development of this article

\section{MATERIALS DESCRIPTION}

The following materials and its mechanical properties detailed below are used both in experimental and FE simulation techniques.

The material of the specimen is an Aluminium 7017-T73 alloy. This alloy, one of the highest- strength aluminium alloys, contains zinc as the primary alloying element, magnesium which produces a marked improvement in precipitation hardening characteristics and chromium which provides an increase of the stress corrosion cracking resistance [20]. The alloy is treated with a T73 heat-treatment, which consists of a heattreatment solution and artificial aging that leaves the alloy beyond the point of maximum strength and achieves the best stress corrosion resistance. Aluminium 7017 alloy is mainly used in armoured vehicles. The behavior of this material is selected because it is a highly resistant aluminum alloy which behavior in service will be subjected to high speeds and it has a good ductility that is useful to define the behavior of the damping disks. [21].

Table 1 shows the mechanical properties of the Aluminum 7017-T73 alloy at high rates, the ones of the lead used for the damping rings and also the ones of the steel used in the Hopkinson bars and the interruption fixture at high strain rates.

TABLE I

Mechanical properties of the materials used both in experimental and FE simulation Techniques.

\begin{tabular}{|l|c|c|c|}
\hline & Aluminum 7017-T73 & Lead & Steel \\
\hline Poisson's ratio & 0.3 & 0.45 & 0.3 \\
\hline Young's modulus $(\mathrm{GPa})$ & 63 & 10 & 202 \\
\hline Density $\left(\mathrm{Kg} / \mathrm{m}^{3}\right)$ & 2710 & 11000 & 7850 \\
\hline Yield strength $(\mathrm{MPa})$ & 507 & 33 & 550 \\
\hline Ultimate tensile strength (UTS) (MPa) & 563 & 42 & 650 \\
\hline Ductility & 0.12 & 0.6 & 0.14 \\
\hline
\end{tabular}

As for the FE analysis, other materials have been simulated besides lead to study the influence of the damping rings material on the interruption process. A X-Material is used in order to find the influence of the damping rings density on the specimen strain and different compositions of glass fiber-reinforced polystyrene (GF-polystyrene) are used to find the influence of the other properties.

\section{Methodology}

The interruption mechanism is based on the use of two damping rings working as buffers which are enclosed in an external interruption fixture. They can absorb the impact energy by deforming plastically and therefore allowing a tensile stress distribution in the specimen. Otherwise the specimen would receive an undesired compressive stress wave. [22]. 
A number of research works have designed the interruption of SHTB experiments [23], [24]. In the beginning of 90s, a method to interrupt Hopkinson experiments was developed by Nemat- Nasser et al [25], which was based on the absorption of the reflected waves for controlling the deformation level of the specimen. Ma et al [26] developed a high-speed tensile facility to interrupt the fracture tests for pure copper specimen at different levels of elongation. El-Saeid Essa et al [27] developed a convenient approach to interrupt a SHTB test, which is described below. They modified the ends of the incident and transmission bars, and used an external interruption fixture to control the deformation level of the specimen. Such system can control the elongation of specimens at high strain rate using a modified SHTB.

The influence of the designed external fixture on the stress waves and also the ability of the system to support the interruption of the deformation process must be considered in the numerical analysis and verified by the experimental results. Strain-stress responses at various strain rates is an important aspect of the dynamic behaviour of materials up to the point where the specimen breaks. A modified SHTB on which an external interruption fixture was mounted was developed by González-Lezcano et al and installed in the Universidad Carlos III de Madrid Engineering Laboratory (Madrid, Spain), as detailed in [28].

The above-mentioned paper relating to an anterior experimental work made by one of the authors of this paper et al shows the validation of the numerical results using one only geometry of the damping rings which was previously set. Therefore, the results presented in this paper are obtained from FEA rather than experiments since the validation of the FEA model has already been determined. Guidelines in order to determine the clear limits produced on strain achieved by using plastic deformation of the damping rings rather than confined compression can be also found in [28]. The numerical technique produces clear limits on strain, which are achieved using the following formula:

$$
\Delta \mathbf{L} \max =\mathbf{L} 0\left(\mathbf{e}^{\boldsymbol{\varepsilon}}-\mathbf{1}\right)
$$

where $\mathrm{L}_{0}$ is the initial length of the specimen and $\varepsilon$ is the specimen strain.

The external interruption fixture stops the test at predetermined elongation before reaching the material's failure strength. The system developed in 2003 included damping rings to attenuate the effects of the compressive waves produced as result of including the external interruption fixture. Lead is considered for the damping rings.

In the modified SHTB apparatus, the bars are designed with a non-uniform cross section. Moreover, an increment of the cross-sectional area of the bar ends which are in contact with the specimen is necessary to properly mount the external interruption fixture in parallel with the bars, as shown in figure 8. Such increment of the cross-sectional area of the above-mentioned bar ends does not significantly interfere on the classical SHTB apparatus behavior.

Figure 1 shows the front view of the above-mentioned modified SHTB installed in the Universidad Carlos III de Madrid Engineering Laboratory (Madrid, Spain), including (A) the external interruption fixture (i.e., a cylindrical element that consists of two steel pieces that are screwed to facilitate a proper access to the specimen), (B) an increase of the cross-sectional area of the bar ends to which the specimen is screwed, and (C) two damping rings made of a buffer material placed on the interface between the bars and the external interruption fixture.

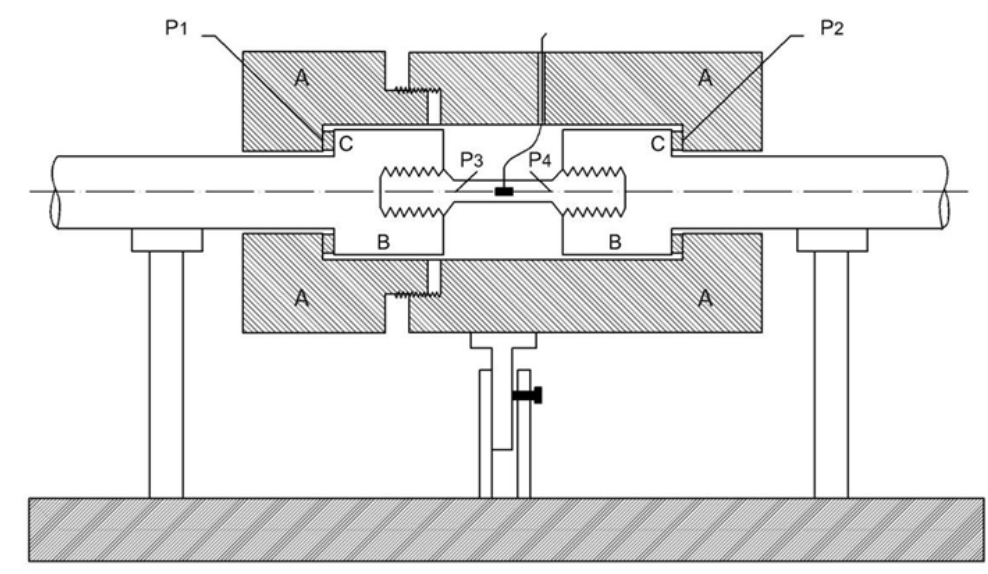

Figure 1. Front view of the external interruption fixture mounted on a modified SHTB [33].

.Following the ASTM Standards and Recommendations [29] and Rodríguez [30], tension specimens are generally dog-bone shaped. They are placed in specially designed grips screwed into the threaded incident and transmission bars. Tension specimens with threaded ends are generally fabricated from $6.35-\mathrm{mm}$ diameter bar stock. To accept the threaded specimen, aluminum anvils are attached to the incident and transmission bar ends 
with threaded holes. The length of reduced section of the specimen (L) is $25.4 \mathrm{~mm}$ long, the diameter of such reduced section (D) is $6.35 \mathrm{~mm}$ long, the threaded zone diameter $(\mathrm{Dr})$ is $12 \mathrm{~mm}$ long, and the threaded zone length $(\mathrm{Lr})$ is $14 \mathrm{~mm}$ long.

The interruption fixture performs as an actual rigid body avoiding the expansion of the damping rings. Therefore, the damping rings deform when the specimen deforms. This can be achieved fabricating a robust element with the suitable mechanical properties and whose dimensions are consistent with the aim pursued. The interruption fixture maintains a constant length between the damping rings allowing them to stop the experiment. The elongation of the test specimen can therefore be controlled by the length of the external interruption fixture. The element is manufactured in two threaded pieces to permit an easy access to the specimen. The damping rings can be suitaby adjusted by means of the threaded pieces.

Figure 2 shows a picture of the two-piece external interruption fixture when (a) unscrewed to insert the damping rings or access the specimen and when (b) screwed. Their main purpose is allowing deformation in the specimen until the maximum strain before failure strength can be reached. In addition, it can be observed that the damping rings enter a wide zone of plastic deformation. Such plastic deformation actually absorbs the undesired compressive stress wave. Homogeneous stress and strain in the specimen are considered. However, the stress distribution depends on the stress pulse applied.
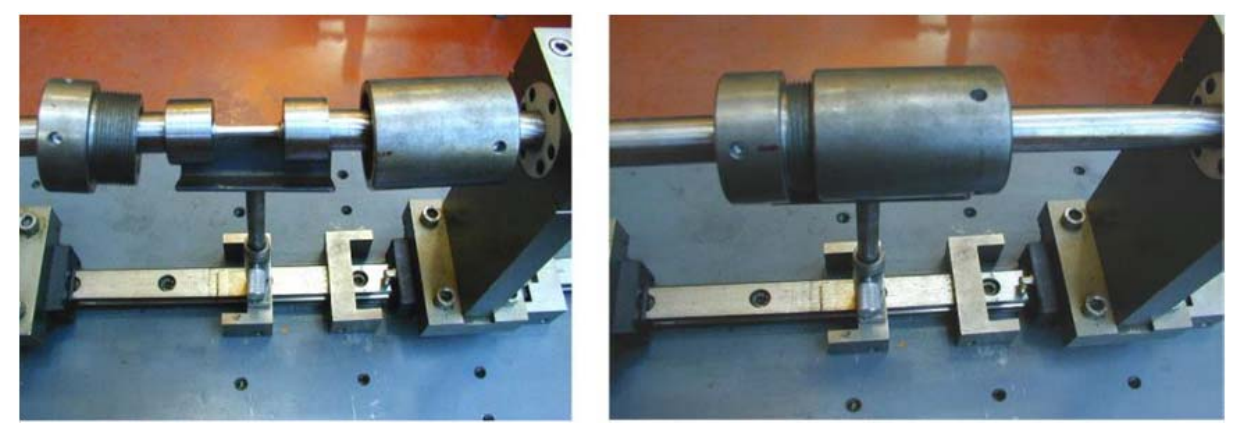

Figure 2. External interruption fixture when (a) unscrewed to insert the damping rings or access the specimen and (b) when screwed [33].

Damping rings must be designed to adjust the material being tested. The election of the material is extremely important since they must be ductile enough for energy absorption and strong enough to attenuate the incident wave.

Although lead is the damping rings material used in the SHTB experiment using the apparatus installed in the Universidad Carlos III de Madrid Engineering Laboratory, other materials have been simulated to study the influence of the material properties on the interruption process. A X- Material is used in order to find the influence of the damping rings density on the specimen strain and different compositions of glass fiberreinforced polystyrene (GF-polystyrene) are used to find the influence of the other properties, as discussed below.

\section{FINITE ELEMENT (FE) SIMULATIONS METHODOLOGY}

The finite element (FE) method is a powerful technique originally developed for numerical solution of complex problems in structural mechanics and it remains the method of choice for complex systems. In this paper the FE simulations are performed using the finite element program ABAQUS (from ABAQUS, Inc.). The finite element models described herein are created with ABAQUS/CAE [31]. ABAQUS/Explicit code is used for the calculations to study the precise dynamical phenomena in the specimen. Instances are meshed using quadrilateral elements (CAX4R) and a structured meshing. In general, structured meshing provides the most control over the mesh that ABAQUS/CAE generates. ABAQUS/CAE respects seed distribution wherever possible when generating a structured mesh.

For modelling, a strain-rate sensitive model is employed. The model is complemented by assuming that the transverse stresses are zero. A 1D code is developed on the basis of the Godunov scheme [32].

Three FE models are established. A classical SHTB model without the external interruption fixture (Model1), a modified SHTB model increasing the cross-sectional area of the bar ends which are in contact with the specimen but without the external interruption fixture (Model-2), and a modified SHTB model with the entire interruption device including the fixture and the damping rings enclosed within (Model-3

Finite element simulations of high-strain-rate tension experiments have been performed on Aluminum 
7017-T73 alloy specimens using different dimensions of the damping rings made of lead at a strain rate of $1,000 \mathrm{~s}^{-1}$ in order to reproduce the same stress wave observed in experiments accomplished with SHTB apparatus. The classical SHTB (Model-1) has already been validated with the SHTB apparatus in which high strain rate tensile experiments are made on Aluminum 7017-T73 alloy specimens [27-28]. The modeling results of Model-1 correlate well with the SHTB experimental results when carried out without interruption, confirming the validity of the FE model.

The strike is modeled by a rigid body impacting the end of the incident bar. The incident and transmitted waves are achieved in the same nodes of the FE model, which correspond to the strain gauge positions on the real bars. The strike is modeled under a rigid-body assumption since this issue does not influence the results, always provided that the dimensions of the projectile are insignificant in comparison with the ones relating to the incident and transmission bars. Once the stress wave is simulated reproducing the effect of the impact, no projectile is necessary to be added to the model.

Details of FE meshes of the three models for validating interrupted mechanisms can be found below: the classical SHTB model without interruption (Model-1 shown in fig. 3), the modified SHTB model when the cross-sectional area of the bar ends which are in contact with the specimen are increased but without assembling the interruption device (Model-2 shown in fig. 4), and the modified SHTB model with the entire interruption mechanism including damping rings (red zones) enclosed in the interruption fixture (blue zones). (Model-3 shown in fig. 5).

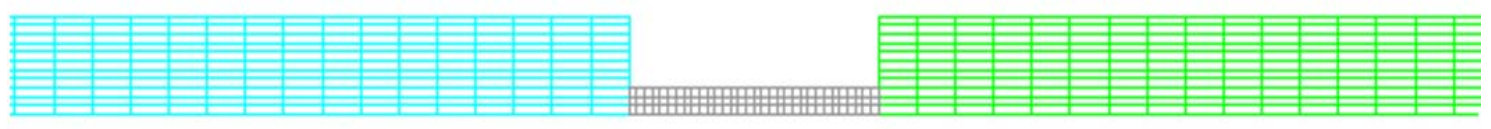

Figure 3. Structured mesh in the classical SHTB model without interruption (Model-1) [33].

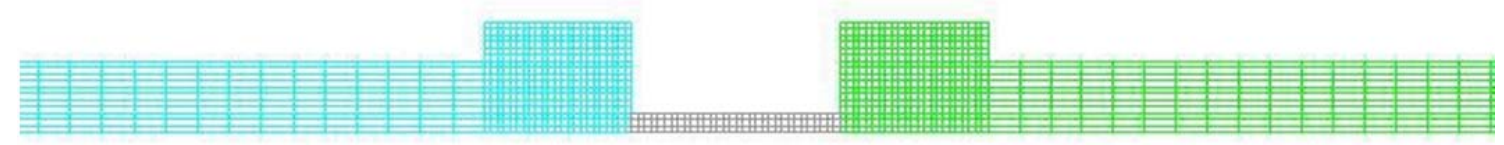

Figure 4. Structured mesh in the modified SHTB model (Model-2) [33].

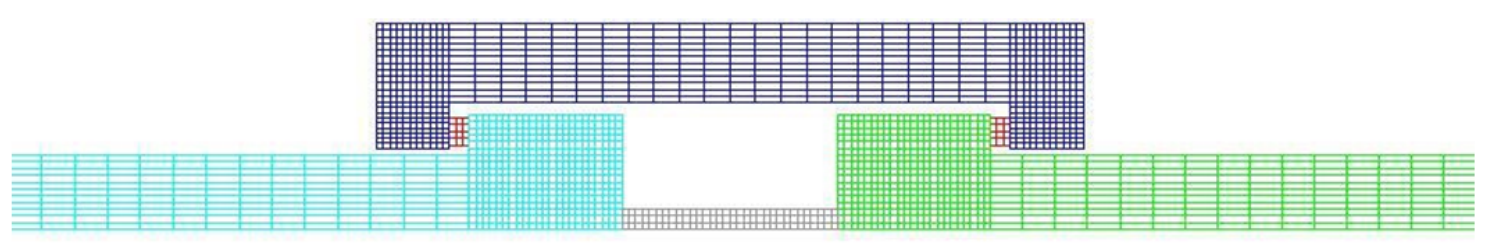

Figure 5. Structured mesh in the modified SHTB model (Model-3) [33].

The numerical models of both the classical SHTB model (Model-1) and the modified SHTB model when the cross-sectional area of the bar ends which are in contact with the specimen is increased (Model-2) consist of:

- $\quad$ Number of nodes: 10.596

- $\quad$ Number of elements: 9.678

The numerical model of the modified SHTB model when using an interruption device including two damping rings enclosed in an interruption fixture (Model-3) consists of:

- Number of nodes: 11.437

- $\quad$ Number of elements: 10.428

\section{ANALYSIS AND DISCUSSION}

Finite-element (FE) simulations of high-strain-rate tension experiments are accomplished on Aluminum 7017-T73 alloy specimens when using 4-mm thick damping rings with a cross- sectional area of $364.4 \mathrm{~mm}^{2}$ (Model-3). All data shown below are relevant to the centre of the specimen (i.e., the area in which stresses and strains in the specimen reach their maximum values).

The main goal of this simulation is gathering information about the specimen's behaviour at high strain rates. Therefore, if the strain rate in the specimen decreases and high strain rates can not be maintained, the 
experiment must not be acceptable. Strain rate-time curves can be obtained in each case after finding the time derivative of the strain-time curves previously depicted.

Figure 6 shows a comparison between the strain-time curves at the centre of the specimen for both the modified SHTB without the interruption device (Model-2) and the modified SHTB using 4-mm thick damping rings with a cross-sectional area of $364.4 \mathrm{~mm}^{2}$ (Model-3).

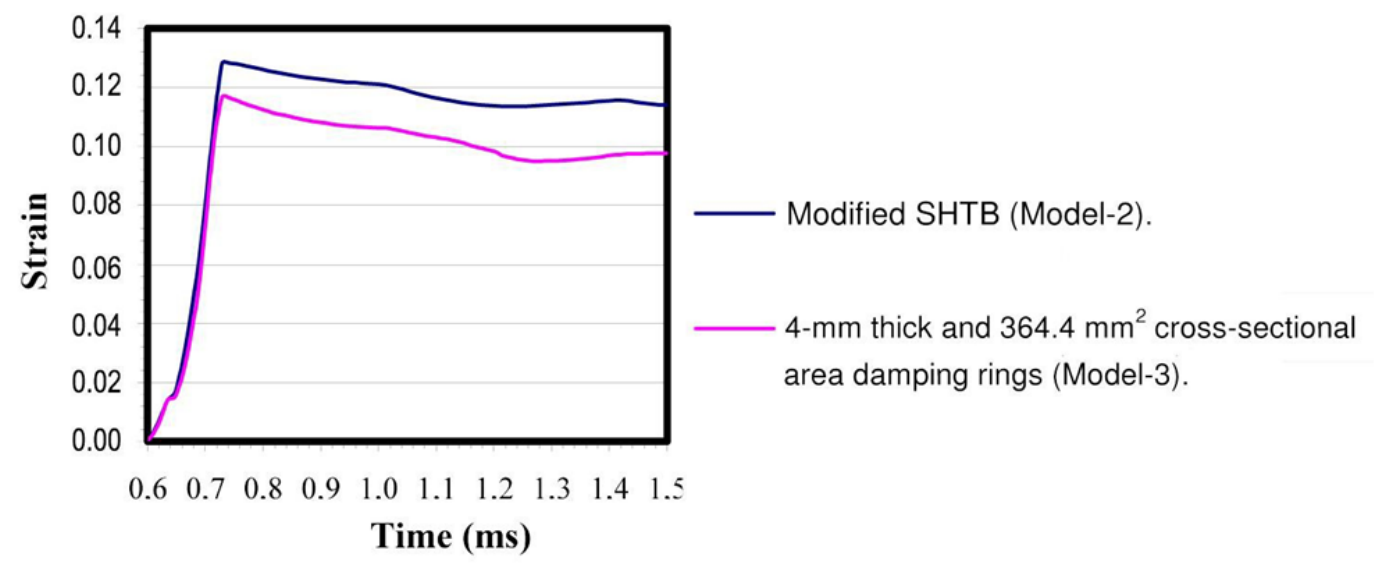

Figure 6. Comparison between the strain-time curves at the centre of the specimen for both models (Model-2) and (Model-3).

Figure 6 shows that failure area is avoided (0.12) when the system is damped.

When the damping rings material is different than lead, the results of the experiments vary. Therefore, it is necessary to accomplish a numerical analysis of the influence of the damping rings material on the interrupted dynamic tension experiment results.

Various simulations have been carried out varying the material used to fabricate the damping rings. The properties of the materials selected are similar to those of lead, whose interrupting possibilities are proven. The properties analysed are density, Poisson's ratio, ductility, ultimate tensile strength (UTS), yield strength, and Young's modulus.

The starting point is the experiment carried out using 4-mm thick damping rings with a cross- sectional area of $364.4 \mathrm{~mm}^{2}$ (Model-3) and an impact speed of 10,000 mm/s.

The first properties considered are those which do not affect the stress-strain curve of the buffer material, i.e., density and Poisson's ratio.

Since the density of lead is considerably high, the materials selected happen to show a lower density but their remaining properties must keep lead-like properties. Thus, the strain variation in the specimen is due only to the variation of density and therefore density-dependence can be conveniently studied separately avoiding the influence of the remaining properties.

Table 2 shows the properties of the materials selected to have an in-depth study of the influence of density on the specimen strain. The in-between X-Material is a fictitious material since no actual material was found showing such properties. X-Material is used in order to find the influence of the damping rings density on the specimen strain.

TABLE II

Properties of different materials to study the influence of density on the interruption process.

\begin{tabular}{|c|c|c|c|c|c|c|}
\hline \multirow{2}{*}{ Materials } & \multicolumn{5}{|c|}{ Properties } \\
\cline { 2 - 7 } & $\begin{array}{c}\text { Density x } 10^{3} \\
\left(\mathrm{Kg} \cdot \mathrm{m}^{-3}\right)\end{array}$ & $\begin{array}{c}\text { Poisson's } \\
\text { ratio }\end{array}$ & $\begin{array}{c}\text { Young's } \\
\text { modulus } \\
(\mathrm{GPa})\end{array}$ & $\begin{array}{c}\text { Yield } \\
\text { strength } \\
(\mathrm{MPa})\end{array}$ & $\begin{array}{c}\text { UTS } \\
(\mathrm{MPa})\end{array}$ & Ductility \\
\hline Lead & 11 & 0.45 & 10 & 33 & 55 & 0.6 \\
\hline X-Material & 5 & 0.45 & 10 & 33 & 55 & 0.6 \\
\hline Polystyrene & 1.5 & 0.45 & 10 & 33 & 55 & 0.6 \\
\hline
\end{tabular}


Fig. 7 shows the strain-time curves.

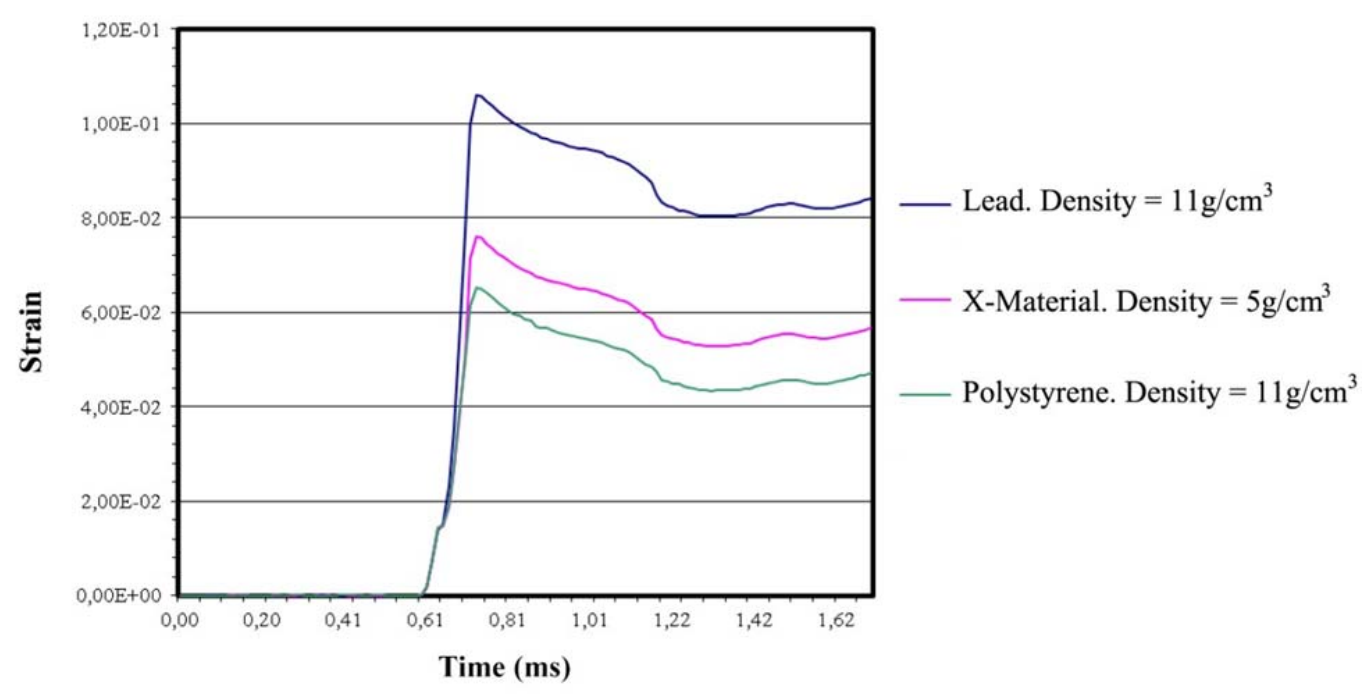

Figure 7. Strain-time curves showing the influence of density on the interruption process.

It can be demonstrated that the influence of the damping rings density on the interruption of the experiment is relevant. The material with the lower density has the stronger influence on the interruption process.

This effect is due to the direct influence of density on the transmission wave speed $(c=\sqrt{ } E / \rho)$. The stress wave propagation speed has a direct influence on the stress-strain relation as shown in equation.

$$
\sigma=\rho \mathrm{c}\left(\varepsilon_{1}\right) \mathrm{v}
$$

Hence, when density is diminished, the stress wave propagation speed (c) is enhanced and therefore the stress increases. Therefore the interruption effect is more severe.

Consequently, polymers are materials which have a great performance as buffers due to their low density. The remaining properties of polymers should be studied to find whether they can be used as buffers.

The material selected to study the influence of Poisson's ratio on the interruption process is a composite of glass fiber-reinforced polystyrene (GF-polystyrene) using different compositions of the reinforcement that will provide the material with an acceptable range of the property studied. Table 3 shows the variation of the composition of GF-polystyrene to study the influence of Poisson's ratio.

TABLE III

Properties of different compositions of GF-Polystyrene to study the influence of Poisson's ratio on the interruption process.

\begin{tabular}{|c|c|c|c|c|c|c|}
\hline \multirow[b]{2}{*}{ Materials } & \multicolumn{6}{|c|}{ Properties } \\
\hline & $\begin{array}{c}\text { Density x } \\
10^{3} \\
\left(\mathrm{Kg} \cdot \mathrm{m}^{-3}\right)\end{array}$ & $\begin{array}{l}\text { Poisson's } \\
\text { ratio }\end{array}$ & $\begin{array}{c}\text { Young's } \\
\text { modulus } \\
(\mathrm{GPa})\end{array}$ & $\begin{array}{c}\text { Yield } \\
\text { strength } \\
(\mathrm{MPa})\end{array}$ & $\begin{array}{c}\text { UTS } \\
(\mathrm{MPa})\end{array}$ & Ductility \\
\hline GF-Polystyrene-1 & 1.5 & 0.34 & 10 & 38 & 55 & 0.6 \\
\hline GF-Polystyrene-2 & 1.5 & 0.39 & 10 & 38 & 55 & 0.6 \\
\hline
\end{tabular}


Fig. 8. shows the strain-time curves in the centre of the specimen using the above-mentioned materials.

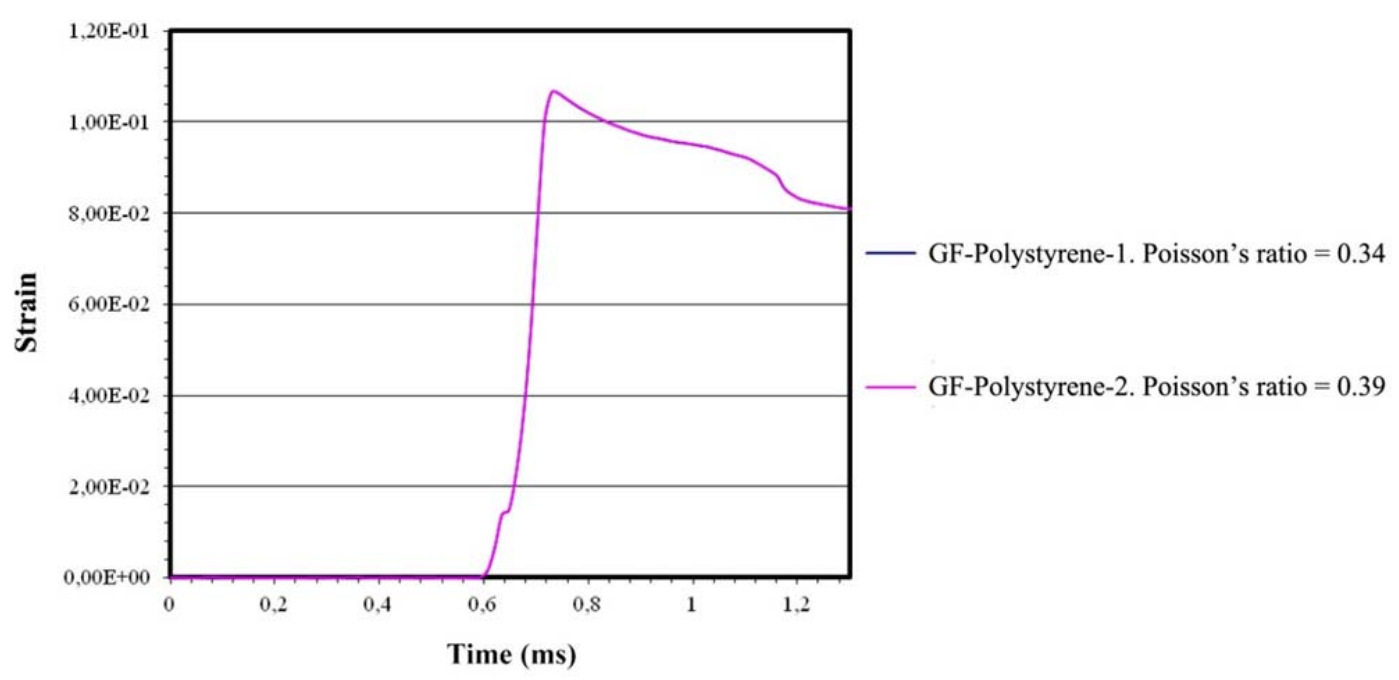

Figure 8. Strain-time curves showing the influence of Poisson's ratio on the interruption process.

Fig. 8 illustrates that there is no relevant effect of Poisson's ratio when interrupting the SHTB experiment.

Moreover, the influence of ductility of the damping rings on the maximum strain of the specimen can also be analysed. GF-polystyrene is used varying such property solely. Table 4 shows the comparison between the different values of ductility for three compositions of GF-polystyrenes.

TABLE IV

Properties of different compositions of GF-Polystyrene to study the influence of ductility on the interruption process.

\begin{tabular}{|c|c|c|c|c|c|c|}
\hline \multirow{2}{*}{ Materials } & \multicolumn{7}{|c|}{ Properties } \\
\cline { 2 - 7 } & $\begin{array}{c}\text { Density } \mathrm{x} \\
10^{3} \\
\left(\mathrm{Kg} \cdot \mathrm{m}^{-3}\right)\end{array}$ & $\begin{array}{c}\text { Poisson's } \\
\text { ratio }\end{array}$ & $\begin{array}{c}\text { Young's } \\
\text { modulus } \\
(\mathrm{GPa})\end{array}$ & $\begin{array}{c}\text { Yield } \\
\text { strength } \\
(\mathrm{MPa})\end{array}$ & $\begin{array}{c}\text { UTS } \\
(\mathrm{MPa})\end{array}$ & Ductility \\
\hline GF-Polystyrene-2A & 1.5 & 0.39 & 10 & 38 & 55 & 0.6 \\
\hline GF-Polystyrene-2B & 1.5 & 0.39 & 10 & 38 & 55 & 2 \\
\hline GF-Polystyrene-2C & 1.5 & 0.39 & 10 & 38 & 55 & 8 \\
\hline
\end{tabular}

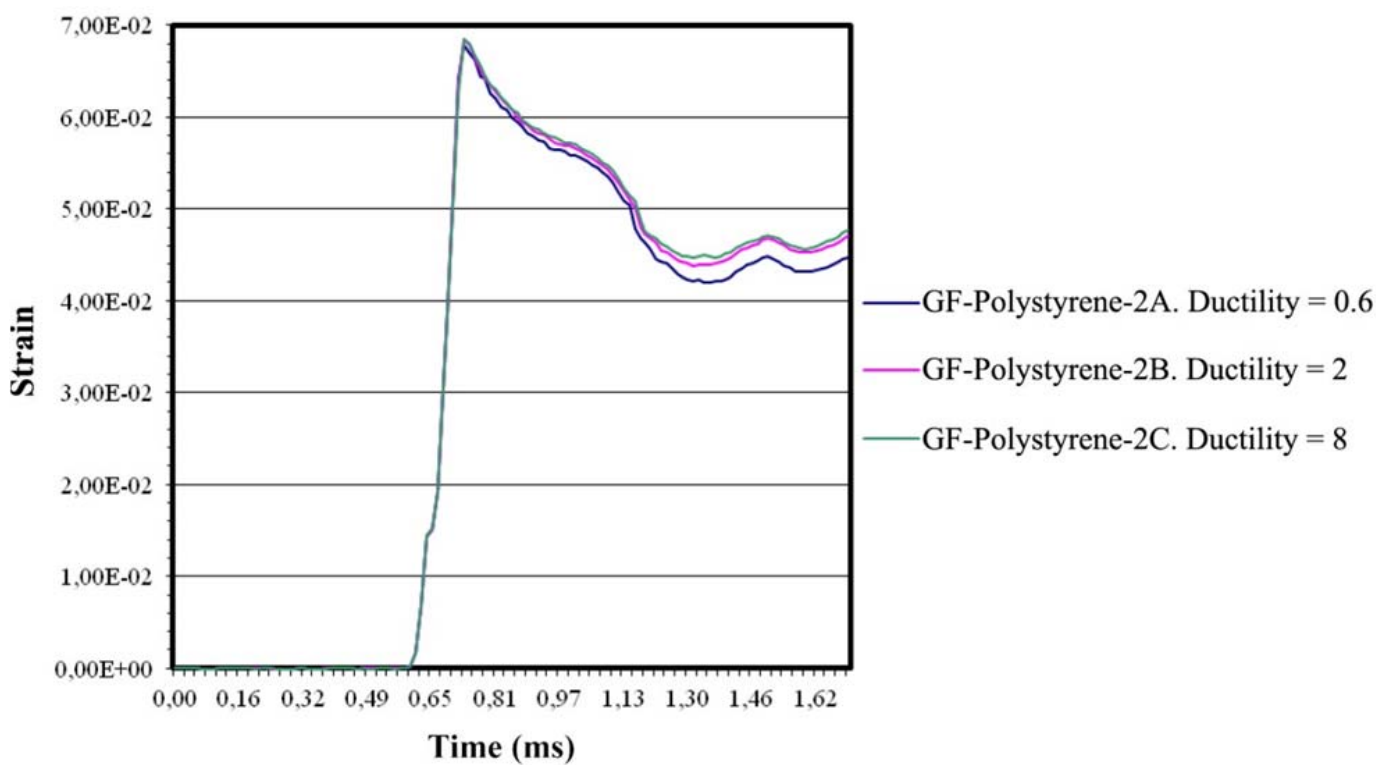

Figure 9. Strain-time curves showing the influence of ductility on the interruption process. 
Although the differences found are minimal, it can be observed that some of the curves decline with more intensity than others after reaching the maximum strain value. The interruption becomes more abrupt as the ductility gets lower. Fig. 10 shows a comparison for a better understanding of the effect.

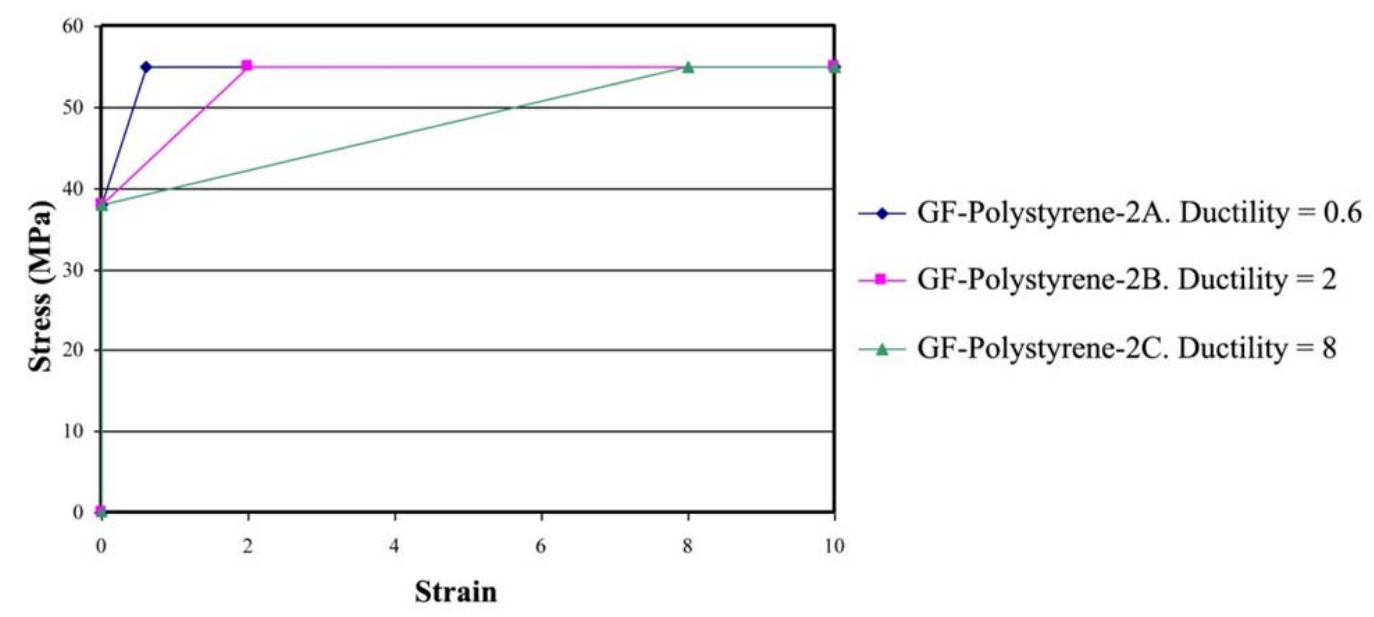

Figure 10. Stress-strain curves of GF-Polystyrene to study the influence of ductility on the interruption process.

It can be observed that ABAQUS considers a DC line beyond ultimate tensile strength (UTS). The material that yields a wider area, as shown in fig. 10, is the one that is providing a more important interruption effect. GF-Polystyrene-2A is the material presenting a higher slope and a higher area. Consequently the specimen deformation will be less relevant. It can therefore be observed that buffers with a higher ductility have a more significant contribution on the compression wave absorption without affecting the interruption efficiency.

To analyse the influence of ultimate tensile strength (UTS) on the interruption process, the materials selected are variations in the GF polystyrene compositions, as shown in table 5

TABLE V

Properties of different GF-Polystyrene to study the influence of ultimate tensile strength (UTS) on the interruption process.

\begin{tabular}{|c|c|c|c|c|c|c|}
\hline \multirow{2}{*}{ Materials } & \multicolumn{7}{|c|}{ Properties } & \\
\cline { 2 - 7 } & $\begin{array}{c}\text { Density } \\
\times 10^{3} \\
\left(\mathrm{Kg} \cdot \mathrm{m}^{-3}\right)\end{array}$ & $\begin{array}{c}\text { Poisson's } \\
\text { ratio }\end{array}$ & $\begin{array}{c}\text { Young's } \\
\text { modulus } \\
(\mathrm{GPa})\end{array}$ & $\begin{array}{c}\text { Yield } \\
\text { strength } \\
(\mathrm{MPa})\end{array}$ & $\begin{array}{c}\text { UTS } \\
(\mathrm{MPa})\end{array}$ & Ductility \\
\hline GF-Polystyrene-2A1 & 1.5 & 0.39 & 10 & 38 & 11 & 0.6 \\
\hline GF-Polystyrene-2A2 & 1.5 & 0.39 & 10 & 38 & 55 & 0.6 \\
\hline GF-Polystyrene-2A3 & 1.5 & 0.39 & 10 & 38 & 90 & 0.6 \\
\hline
\end{tabular}




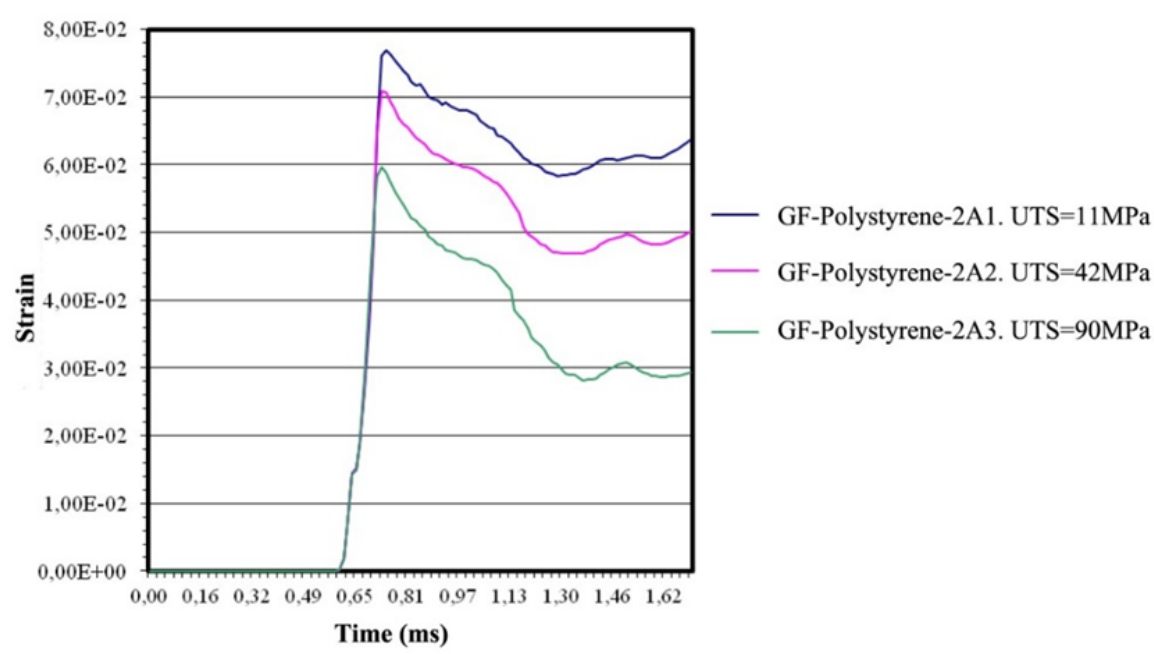

Fig. 11. Strain-time curves of different compositions of GF-Polystyrene to study the influence of ductility on the interruption process.

It can be seen that the influence of ultimate tensile strength on the specimen strain is definitely significant since a higher UTS implies a substantial decrease of the specimen strain. Moreover, highest values of UTS as those reached when using GF-Polystyrene-2A3 affect the compression effect severely.

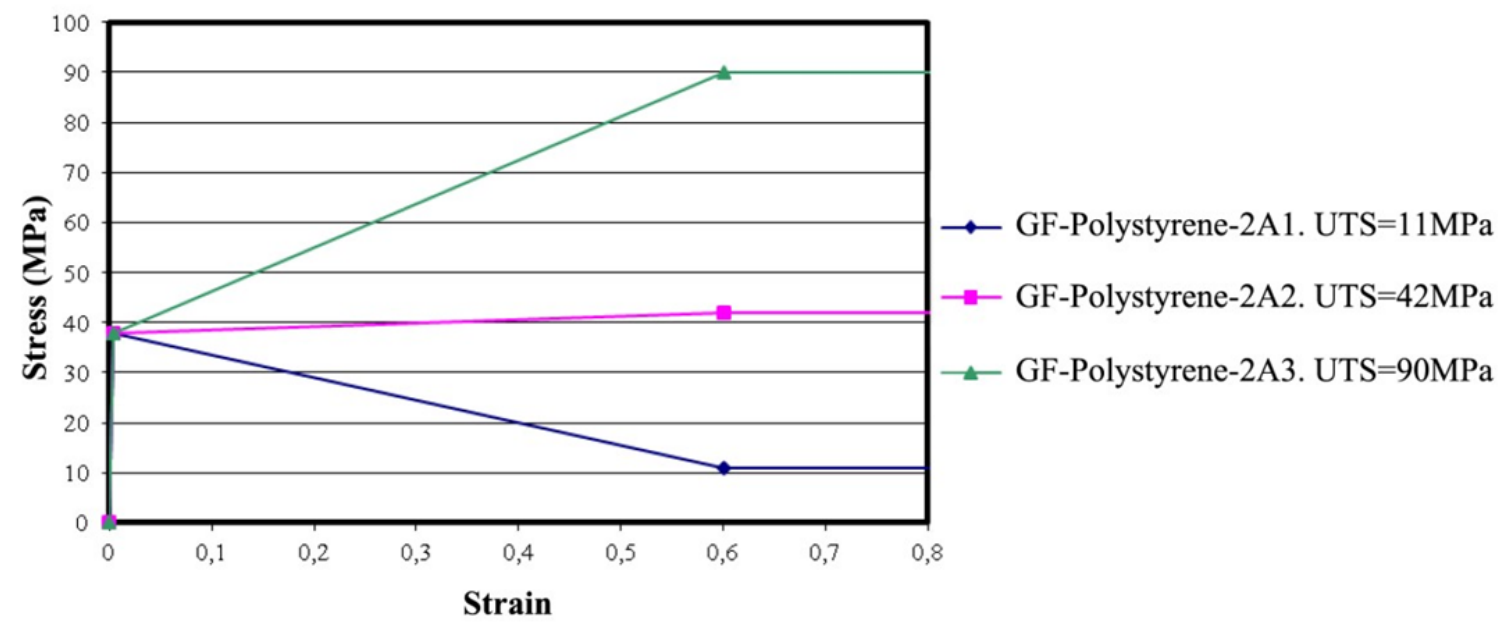

Figure 12.- Stress-Strain curves of different compositions of GF-Polystyrene to study the influence of UTS on the interruption process.

Fig. 12 illustrates that stress-strain curves are considerably different for each material and therefore their interruption effects are variable. As it was observed when studying the influence of ductility, the material that yields a wider area is the one that is providing a more significant interruption effect and vice versa. GF-Polystyrene-2A1 is the material presenting a higher slope and a higher area.

To analyse the influence of yield strength on the interruption process, the materials selected are also variations in the GF polystyrene compositions, as shown in table 6. 
TABLE VI

Properties of different compositions of GF-Polystyrene to study the influence of yield strength on the interruption process.

\begin{tabular}{|c|c|c|c|c|c|c|}
\hline \multirow{2}{*}{ Materials } & \multicolumn{6}{|c|}{ Properties } \\
\cline { 2 - 7 } & $\begin{array}{c}\text { Density } \\
\mathrm{x} 10^{3} \\
\left(\mathrm{Kg} \cdot \mathrm{m}^{-3}\right)\end{array}$ & $\begin{array}{c}\text { Poisson's } \\
\text { ratio }\end{array}$ & $\begin{array}{c}\text { Young's } \\
\text { modulus } \\
(\mathrm{GPa})\end{array}$ & $\begin{array}{c}\text { Yield } \\
\text { strength } \\
(\mathrm{MPa})\end{array}$ & $\begin{array}{c}\text { UTS } \\
(\mathrm{MPa})\end{array}$ & Ductility \\
\hline GF-Polystyrene-2A3A & 1.5 & 0.39 & 10 & 38 & 90 & 0.6 \\
\hline GF-Polystyrene-2A3B & 1.5 & 0.39 & 10 & 60 & 90 & 0.6 \\
\hline GF-Polystyrene-2A3C & 1.5 & 0.39 & 10 & 80 & 90 & 0.6 \\
\hline
\end{tabular}

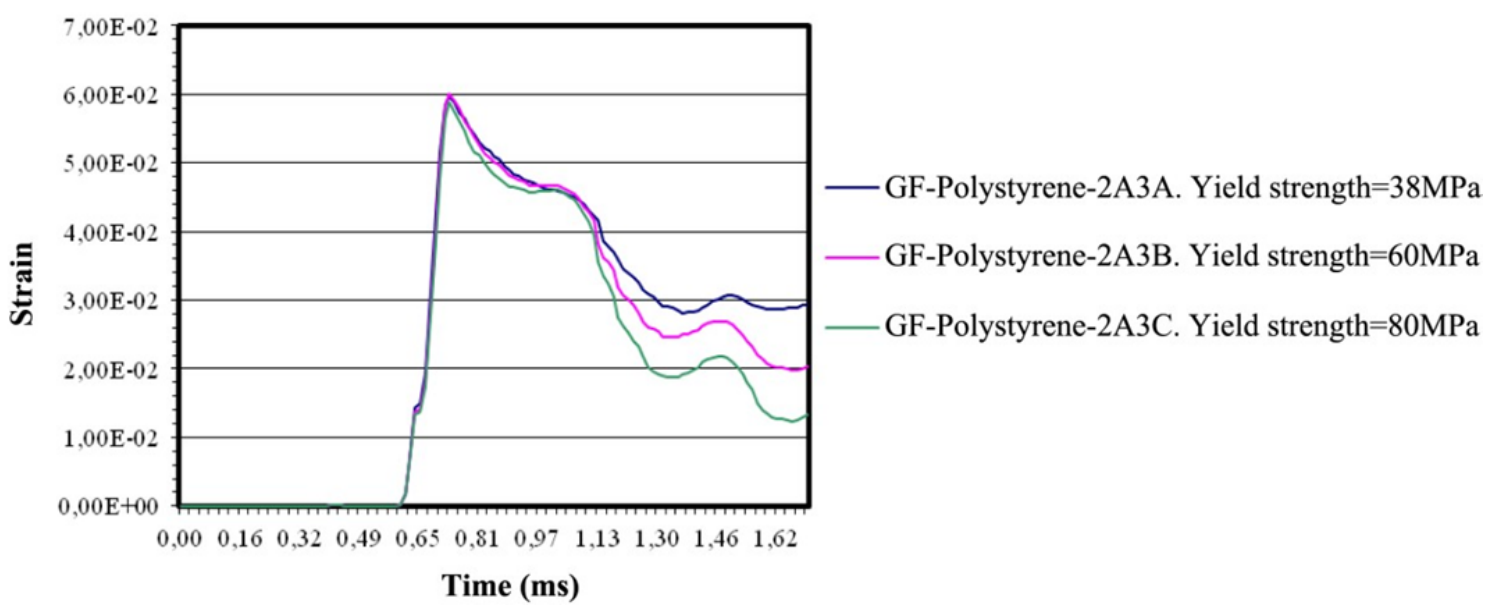

Figure 13. Strain-time curves of different GF-Polystyrene to study the influence of yield strength on the interruption process.

Fig. 13 illustrates an increment in the yield strength that causes the material to absorb energy resulting in an elastic deformation that happens to be subsequently transmitted to the specimen. Such phenomenon should be avoided as far as possible.

To analyse the influence of Young's modulus on the interruption process, the materials selected are variations in the GF polystyrene compositions one more time, as shown in table 7.

TABLE VII

Properties of different compositions of GF-Polystyrene to study the influence of Young's modulus on the interruption process.

\begin{tabular}{|c|c|c|c|c|c|c|}
\hline \multirow{2}{*}{ Materials } & \multicolumn{6}{|c|}{ Properties } \\
\cline { 2 - 7 } & $\begin{array}{c}\text { Density } \mathrm{x} \\
10^{3} \\
\left(\mathrm{Kg} \cdot \mathrm{m}^{-3}\right)\end{array}$ & $\begin{array}{c}\text { Poisson's } \\
\text { ratio }\end{array}$ & $\begin{array}{c}\text { Young's } \\
\text { modulus } \\
(\mathrm{GPa})\end{array}$ & $\begin{array}{c}\text { Yield } \\
\text { strength } \\
(\mathrm{MPa})\end{array}$ & $\begin{array}{c}\text { UTS } \\
(\mathrm{MPa})\end{array}$ & Ductility \\
\hline GF-Polystyrene-2A4 & 1.5 & 0.39 & 1.3 & 38 & 55 & 0.6 \\
\hline GF-Polystyrene-2A5 & 1.5 & 0.39 & 6 & 38 & 55 & 0.6 \\
\hline GF-Polystyrene-2A6 & 1.5 & 0.39 & 10 & 38 & 55 & 0.6 \\
\hline GF-Polystyrene-2A7 & 1.5 & 0.39 & 14 & 38 & 55 & 0.6 \\
\hline
\end{tabular}




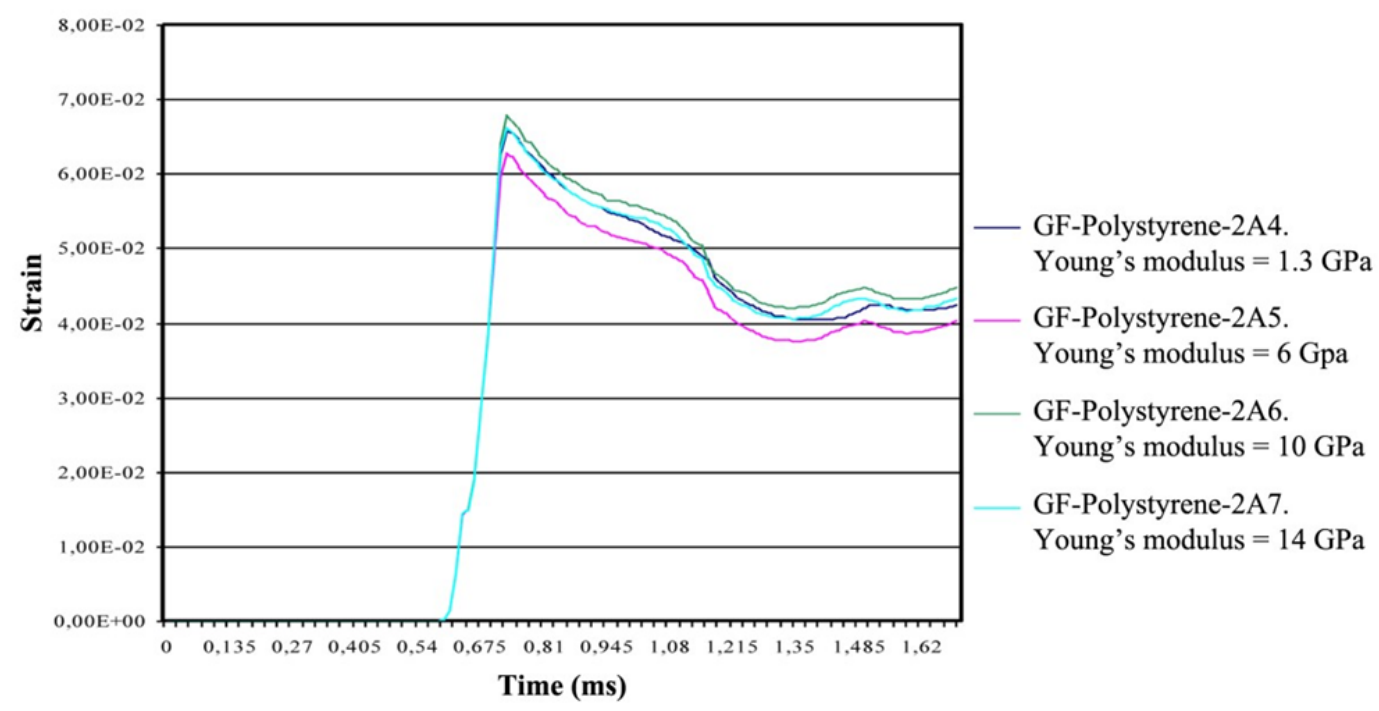

Figure 14. Strain-time curves of different GF-Polystyrene to study the influence of Young's modulus on the interruption process.

Figure 15 shows the comparison between the four stress-strain curves obtained in the specimen when the above-mentioned Young's modulus ranges from $1.3 \mathrm{GPa}$ to $14 \mathrm{GPa}$ respectively.

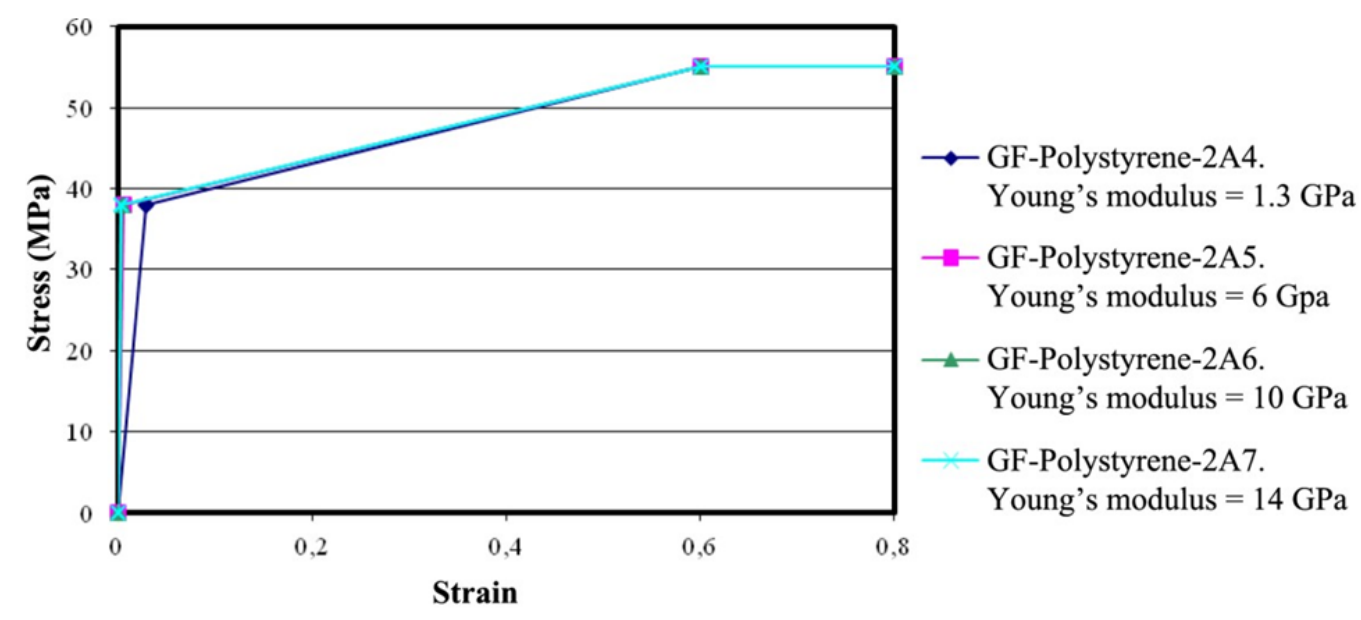

Figure 15.- Stress-Strain curves of different GF-Polystyrene to study the influence of Young's modulus on the interruption process.

There is hardly a variation in the area below the curves and therefore the behaviour of the three types of GFPolystyrene compositions relating to the interruption process can be considered similar. Therefore, the influence of Young's modulus on the interruption process can be neglected.

\section{CONCLUSIONS}

A numerical analysis of the SHTB tests using an external interruption device has been carried out using FE method. The simulation results show that the designed interruption device has a significant effect on the obtained strain in the specimen. Experimental results with the modified SHTB using the interruption device confirmed the validity of the numerical analysis results and the capability of the developed interruption mechanism to stop the dynamic tensile tests at a predetermined elongation value. The elongation of the test specimen can be controlled by the length of the external interruption device.

Results of numerical simulations are presented of SHTB experiments considering different types of damping rings materials. The simulations provide complementary information to the experiments and in-depth understanding of the specimen behaviour.

The modified SHTB model when the cross-sectional area of the bar ends which are in contact with the 
specimen is increased (Model-2) has been validated in a previous work made by one of the authors [28] with the SHTB apparatus where high strain rate tensile experiments are made on Aluminum 7017-T73 alloy specimens. The differences between them are minimal and may therefore be neglected.

The modified SHTB model when using damping rings enclosed in the interruption device (Model-3) has been compared with the modified SHTB when the cross-sectional area of the bar ends which are in contact with the specimen is increased (Model-2). High strain rate tension experiments are performed on Aluminum 7017-T73 alloy specimens using damping rings made of lead.

In this case the observed differences between them are significant and 1D stress wave propagation assumption becomes a challenging issue. However, when analysing the stress- strain conditions in both models, the stress in the specimen results diminished and failure is avoided, as expected, even when maintaining highrate loading.

According to the strains and strain rates observed in the specimen, it has been numerically demonstrated that the density of the damping rings material is definitely a relevant factor in the interruption process. Diminishing the density of the material results in a decrease of the strains found in the specimen and it therefore implies a more intense interruption process. Therefore, the material with the lower density has the stronger influence on the interruption process. Consequently, polymers are materials which have a great performance as buffers due to their low density.

On the contrary, there is no relevant effect of Poisson's ratio when interrupting the SHTB experiment. In view of the above-mentioned results, it is numerically demonstrated that the influence of Poisson's ratio of the damping rings can be considered negligible when compared to the effect of the variation of the damping rings density.

In addition, buffers with a higher ductility have a more significant contribution on the compression wave absorption without affecting the interruption efficiency. Consequently, the material's ductility is another factor influencing the results of the modified SHTB experiments.

It has also been numerically demonstrated the influence of ultimate tensile strength of the damping rings material on the interruption process. As the value of ultimate tensile strength is increased, the strains in the specimen decline considerably.

On the contrary, a variation of the yield strength of the damping rings material is producing a negative effect on the interruption process since the resulting compressive wave becomes enhanced. Therefore, when yield strength is increased the maximum strain values before material failure result hardly affected. Since the main goal is substracting energy from the system by means of plastic deformation, a material with a low yield strength can result balanced if it performs a higher ductility and/or toughness. However, an undesired compression effect is intensified within the specimen. Materials with a low yield strength should be selected for the absorbed energy to be dissipated into plastic deformation.

Since Young's modulus values are linked to yield strength values, both properties are difficult to be studied separately. As previously discussed, the influence of Young's modulus on the interruption process can be neglected.

Finally, it should be emphasized that the validity of the conclusions is limited to the materials having a behaviour resembling the materials considered here.

\section{ACKNOWLEDGMENT}

The authors wish to thank Universidad CEU San Pablo (Madrid, Spain) for facilities and resources provided. The authors would like to express their gratitude to Carlos III de Madrid Engineering Department

\section{REFERENCES}

[1] Harding J, Welsh L. A Tensile Testing Technique for Fiber-Reinforced Composites at Impact Rates of Strain. J Mater Sci 1983;18(6):1810-1826.

[2] Lindholm U, Yeakley L. High Strain-Rate Testing - Tension and Compression. Exp Mech 1968;8(1):1-\&.

[3] Albertini C, Montagnani M. Wave-Propagation Effects in Dynamic Loading. Nucl Eng Des 1976;37(1):115-124.

[4] Nicholas T. Tensile Testing of Materials at High-Rates of Strain. Exp Mech 1981;21(5):177- 185.

[5] Staab G, Gilat A. A Direct Tension Split Hopkinson Bar for High-Strain Rate Testing. BETHEL; BETHEL: SOC EXPERIMENTAL MECHANICS INC; 1990.

[6] Thakur A, NematNasser S, Vecchio K. Dynamic Bauschinger effect. Acta Mater 1996 JUL;44(7):2797-2807.

[7] Verleysen P, Degrieck J. Experimental investigation of the deformation of Hopkinson bar specimens. Int J Impact Eng 2004 MAR;30(3):239-253

[8] Gray GT. Classic Split-Hopkinson Pressure Bar Testing. Materials Park, OH: ASM International, 2000. 2000:462-476. 
[9] Gama BA, Lopatnikov SL, Gillespie JW. Hopkinson bar experimental technique: a critical review. Appl Mech Rev 2004;57(4):223250.

[10] Gerlach R, Kettenbeil C, Petrinic N. A new split Hopkinson tensile bar design. Int JImpact Eng 2012 DEC;50:63-67.

[11] Kolsky H. An Investigation of the Mechanical Properties of Materials at very High Rates of Loading. Proceedings of the Physical Society.Section B 1949;62(11):676.

[12] Rio T, Barbero E, Zaera R, Navarro C. Dynamic tensile behaviour at low temperature of CFRP using a split Hopkinson pressure bar. Composites Sci Technol 2005JAN;65(1):61-71.

[13] Van Slycken J. Advanced Use of a Split Hopkinson Bar Setup-Application to TRIP Steels 2008.

[14] Hamouda A, Hashmi M. Testing of composite materials at high rates of strain: advances and challenges. J Mater Process Technol 1998 MAY 1;77(1-3):327-336.

[15] Gray GT. Classic Split-Hopkinson Pressure Bar Testing. Materials Park, OH: ASM International, 2000. 2000:462-476.

[16] Khlif, M., Masmoudi, N. \& Bradai, C. Polypropylene tensile test under quasi-static and dynamic loading. Materials Science and Technology Conference and Exhibition 2012, MS and T 2012; 2012.

[17] Verleysen P, Benedict V, Verstraete T, Joris D. Numerical study of the influence of the specimen geometry on split Hopkinson bar tensile test results. Lat Am J Solids Struct 2009 SEP;6(3):285-298.

[18] Kaiser MA. Advancements in the split Hopkinson bar test 1998.

[19] Swantek S, Wicks A, Wilson L. An optical method of strain measurement in the split Hopkinson pressure bar. Proceedings of ImacXix: a Conference on Structural Dynamics, Vols 1 and 2 2001;4359:1471-1477.

[20] Pérez-Martín MJ, Erice B, Gálvez F. On the Loading-rate Dependence of the Al 7017-T73 Fracture-initiation Toughness. Procedia Materials Science 2014;3(0):1026-1031.

[21] Rodríguez Pérez J. Análisis y desarrollo de metodologías para la obtención de propiedades mecánicas de materiales a altas velocidades de deformación ya alta temperatura 2002 .

[22] Resnyansky A. Study of inf uence of'loading method on results of the Split Hopkinson Bar test. 2000.

[23] Gerlach R, Kettenbeil C, Petrinic N. A new split Hopkinson tensile bar design. Int J Impact Eng 2012 DEC;50:63-67.

[24] Yang X, Xiong X, Yin Z, Wang H, Wang J, Chen D. Interrupted Test of Advanced High Strength Steel with Tensile Split Hopkinson Bar Method. Exp Mech 2014APR;54(4):641-652.

[25] NEMATNASSER S, ISAACS J, STARRETT J. Hopkinson Techniques for Dynamic Recovery Experiments. Proc R Soc London Ser A-Math Phys Eng Sci 1991 NOV 8:435(1894):371-391.

[26] Ma Dongfang, Chen Danian, Wu Shanxing, Wang Huanran, Hou Yanjun, Cai Canyuan. An interrupted tensile testing at high strain rates for pure copper bars. J Appl Phys 2010 DEC 1;108(11):114902.

[27] Essa YE, Lopez-Puente J, Perez-Castellanos JL. Numerical simulation and experimental study of a mechanism for Hopkinson bar test interruption. J Strain Anal Eng Des 2007 APR;42(3):163-172.

[28] Lezcano R, Essa Y, Perez-Castellanos J. Numerical analysis of interruption processof dynamic tensile tests using a Hopkinson bar. J Phys IV 2003 SEP; $110: 565-570$.

[29] ASTM E8 / E8M-13a, Standard Test Methods for Tension Testing of Metallic Materials,

[30] ASTM International, West Conshohocken, PA, 2013, www.astm.org

[31] Rodríguez Pérez J. Análisis y desarrollo de metodologías para la obtención de propiedades mecánicas de materiales a altas velocidades de deformación ya alta temperatura2002.

[32] ABAQUS, Version 5.8. Hibbit, Karlson and Sorensen, Inc., Pawtucket, RI

[33] Godunov SK, Romenskii EI. Elements of continuum mechanics and conservation laws. : Springer Science \& Business Media; 2003.

[34] González-Lezcano RA, del Río JM. Numerical analysis of the influence of the damping rings'dimensions on interrupted dynamic tension experiment results.J Strain Anaysis 2015;50(8):594-613

\section{AUTHOR PROFILE}

González Lezcano, Roberto Alonso. $\mathrm{PhD}$ in Industrial Engineering, teacher and researcher of the Department of Architecture and Design at the San Pablo CEU University, Madrid, Spain. Member or the research team ARIE CEU.

del Río Campos, Jose Manuel. PhD in Industrial Engineering, teacher and researcher of the Department of Architecture and Design at the San Pablo CEU University, Madrid, Spain. Member or the research team ARIE CEU. 